\title{
RESEARCH ON THE METHODS FOR CALCULATING THE WIDTH OF THE APPROACH CHANNEL TO THE PORT
}

\author{
Vytautas PAULAUSKAS ${ }^{1 *}$, Donatas PAULAUSKAS ${ }^{2}$, Birutė PLAČIENE ${ }^{3}$, Raimondas \\ BARZDŽIUKAS $^{4}$, Gintaras PRIDOTKAS ${ }^{5}$, Ričardas MAKSIMAVIČIUS' ${ }^{6}$, Stefan JANKOWSKI ${ }^{7}$ \\ ${ }^{1-6}$ Dept of Shipping, Klaipeda University, Lithuania \\ ${ }^{7}$ Faculty of Navigation, Maritime University of Szczecin, Poland
}

Received 25 October 2017; revised 21 July 2018; accepted 13 September 2018

\begin{abstract}
An approach channel to the port is a very important part of port infrastructure ensuring navigational safety of the ships entering and departing the port. Various methods used for determining the width of the approach channel to the port provide different results. Sometimes, variations are significant and make difficulties in arriving at the correct final decision. The article analyses diverse methods for research on calculating the width of the approach channel to the port. The obtained results have been verified conducting a real experiment involving real ships passing under similar hydrometeorological conditions. The evaluation of the results and recommendations presented in the article can be used for the optimization and design of approach channels to ports.
\end{abstract}

Keywords: port, ship, manoeuvrability, navigational safety, approach channel.

\section{Introduction}

An approach channel to the port, as the main element of port infrastructure, must provide navigational safety to the ships entering or departing the port. Different methods for estimating the width of the approach channel to the port are based on theoretical calculations (McBride et al. 1998; Ohtsu et al. 2006; Paulauskas 2006, 2013), recommendations, (PIANC 2014; Puertos del Estado 1999), simulations or practical experience and very often show significant differences in the final results and make difficulties in reaching the correct optimal final decision. The results obtained employing various methods need to be evaluated to ensure a request for high navigational safety (Lee, C.-K., Lee, S.-G. 2008). Simultaneously, other problems such as wave penetration to the port area or the extent of investment required, etc. must be solved.

The analysis of the methods for calculating the width of the approach channel to the port is based on the safety-first rule and should stimulate and optimize the final decisions on the parameters for approach channels to ports and, at the same time, take into account research results, new ship manoeuvrability possibilities (Lee, C.-K., Lee, S.-G. 2008; Gucma, Montewka 2005; Groeneveld et al. 2003; Paulauskas, V., Paulauskas, D. 2009), reasonable limitations, external assistance, etc.
The comparative results of the theoretical calculations of approach channels to the port and real situations under similar conditions should assist in choosing limits regarding reasonable risk that can be taken (Groeneveld et al. 2003; Zalewski, Montewka 2007) thus optimizing investment in building approach channels to ports.

\section{Calculating the width of the approach channel to the port}

For calculating the width of the approach channel, the ports attracting similar size ships and having the same navigational and hydro-meteorological conditions were considered (OpenSeaMap 2018) taking a few Baltic Sea ports situated in Gdynia (Poland), Klaipeda (Lithuania), Ventspils (Latvia), Rostock (Germany) and a few West European ports in Dover (UK) and Le-Havre (France), Dunkerk (France) (OpenSeaMap 2018).

All above mentioned ports attract POSTPANAMAX or bigger ships but have similar limitations and, at the same time, special conditions like requirements for using tugs, pilot assistance, etc. Simultaneously, all above mentioned ports have big differences in the width of the approach channel but limitations are very similar. For example, the

${ }^{\star}$ Corresponding author. E-mail: vytautaskltc@gmail.com 
width of the approach channel to the Port of Ventspils is $160 \mathrm{~m}$, the width of the narrowest place in the approach channel to the Port of Gdynia is $140 \mathrm{~m}$, the width of the approach channel to the Port of Klaipeda is $150 \mathrm{~m}$, the width of the approach channel to the Port of Rostock is $130 \mathrm{~m}$, the width of Le-Havre approach channel is $280 \mathrm{~m}$, the width of the narrowest place in Dover approach channel makes $150 \mathrm{~m}$, etc. (OpenSeaMap 2018).

The Port of Ventspils (Figure 1) is visited by SUEZMAX tankers having up to $290 \mathrm{~m}$ in length and up to $50 \mathrm{~m}$ in breadth. The Port of Klaipeda (Figure 2) is visited by POST PANAMAX container vessels having up to 337 $\mathrm{m}$ in length and up to $50 \mathrm{~m}$ in breadth and by SUEZMAX tankers having up to $290 \mathrm{~m}$ in length and up to $48 \mathrm{~m}$ in breadth. The Port of Gdynia (Figure 3 ) is visited by POST PANAMAX container vessels of up to $330 \mathrm{~m}$ in length and up to $50 \mathrm{~m}$ in breadth and by SUEZMAX tankers and bulk curriers having up to $300 \mathrm{~m}$ in length and up to $50 \mathrm{~m}$ in breadth. The Port of Dunkerk (France) (Figure 4) attracts up to Very Large Crude Carriers (VLCC) class tankers of up to $330 \mathrm{~m}$ in length and up to $60 \mathrm{~m}$ in breadth as well as other ships of a similar size.

Significant fluctuations in the width of approach channels show that varying standards or regulations are used in different countries or even in particular ports and can cause difficulties for shipmasters entering ports under specific circumstances (weather conditions, pilot experience, possible tug assistance, etc.). It could be a symptom of a varying safety level for the same type of the manoeuvre.

Standards and recommendations (Grabe 2015; PIANC 2014; Puertos del Estado 1999) focus on the specified results of researches regarding the movement of ships. However, at the same time, traditions and the experience of port pilots have shown there are a lot of exemptions or special conditions creating serious difficulties for port infrastructure designers or managers in making optimal decisions on new approach channels or an increase in ship size considering the existing approach channels.

\section{Theoretical basis for the methods calculating the width of the approach channel to the port}

Parameters for approach channels to ports could be calculated applying theoretical methods (Farzaneh et al. 2008; Paulauskas, V., Paulauskas, D. 2009) and submitting recommendations like PIANC (2014), other standards, etc. In addition, numerical models implemented in simulators could be used (FT 2016). Nowadays, a number of simulators are able to model real ships under real conditions, and therefore for calculating the width of the passing ships (channel width), probability methods, for example maximum distribution method, could be used (Paulauskas 2013).

In order to verify the correctness of the methods used for determining the width of approach channels, the results obtained employing these techniques have to be compared to the outcomes of the real experiments conducted for similar ships and sailing conditions thus making adjustments if necessary.

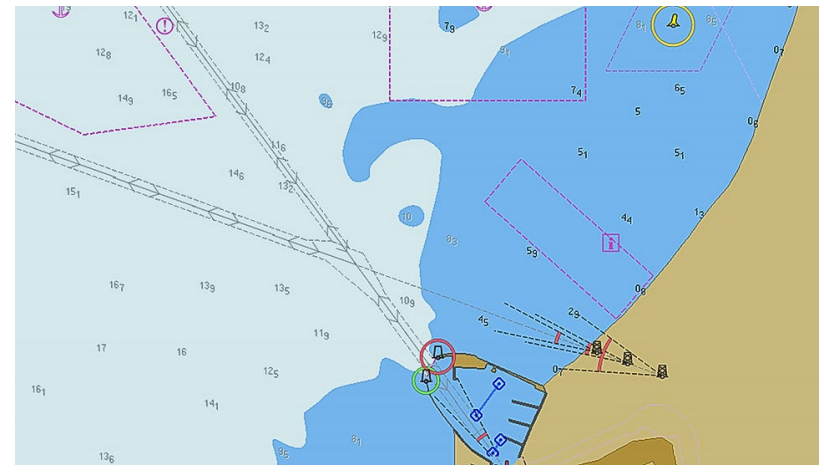

Figure 1. The approach channel to the Port of Ventspils (160 $\mathrm{m}$ in width)

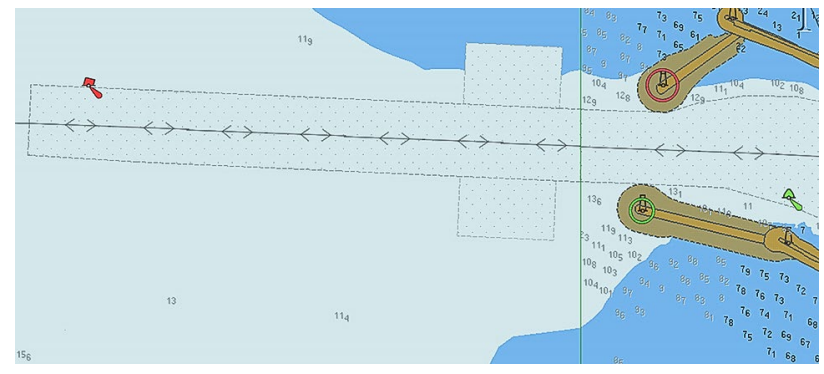

Figure 2. The approach channel to the Port of Klaipeda (150 $\mathrm{m}$ in width)

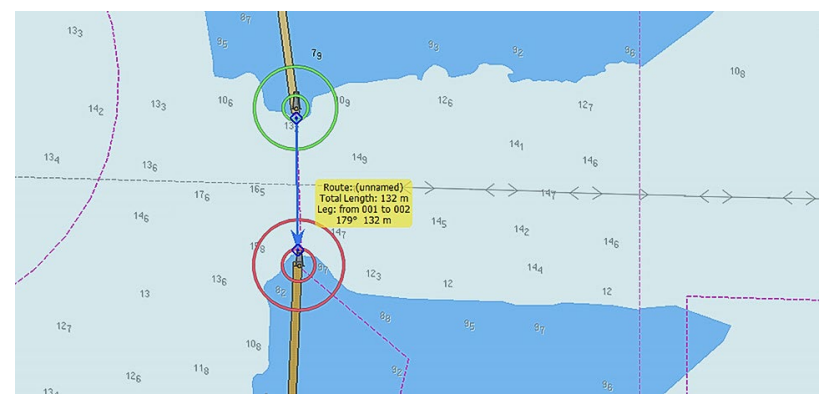

Figure 3. The approach channel and port gate in Gdynia (width of the outside port gate is $132 \mathrm{~m}$, width of the inside port gate is $95 \mathrm{~m}$ )

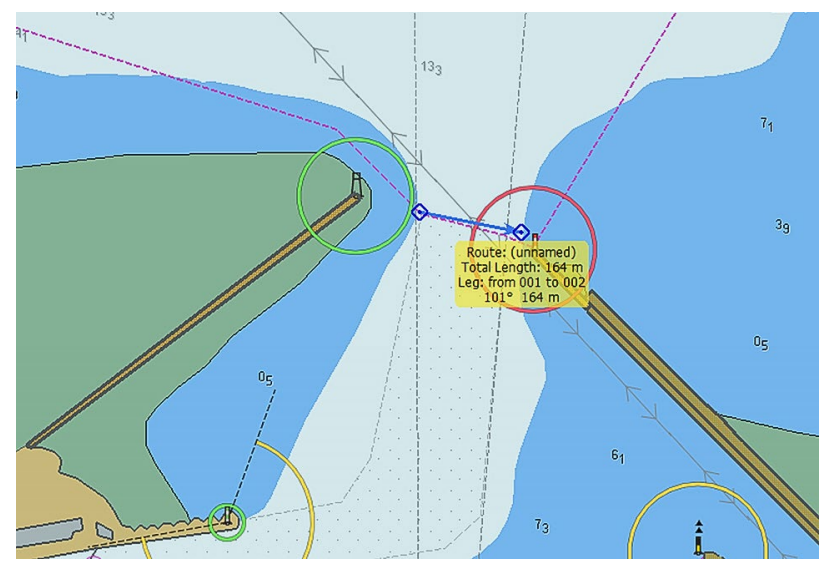

Figure 4. The approach channel to the Port of Dunkerk (width of the port gate is $164 \mathrm{~m}$ with a short area for ship stopping) 
Theoretically, the calculation of the width of approach channels could be made applying the following equation (McBride el al. 1998; Paulauskas, V., Paulauskas, D. 2009; Paulauskas 2013):

$$
B_{k}=L \cdot \sin \beta+B \cdot \cos \beta+L \cdot \sin \Delta K+P^{\prime} \cdot \sigma_{y}+b_{n},
$$

where: $L$ - ship's length; $B$ - ship's breadth; $\beta$ - drift angle of the ship (no more than $5^{\circ}$ is recommended for big ships in approach channels to ports ); $\Delta K$ - sway angle of the ship along the course while heading through the approach channel (no more than $2^{\circ}$ is recommended for big ships); $b_{n}$ - navigational spare depends of the stability of channel slops and the fixed accuracy of the ship position; $P^{\prime}$ - probability maintenance factor in navigation (when probability is $95 \%$, this coefficient should be not less than 2.5; for Liquefied Natural Gas (LNG) tankers, probability reaches $99.7 \%$, and this coefficient should be at least 3); $\sigma_{y}$ - the accuracy of the ship position along the channel axis, for example, the accuracy of the ship position, the sensitivity of the leading line, etc.

The drift angle of the ship sailing to the approach channel can be calculated as follows:

$$
\beta=\operatorname{tg} \frac{v_{d}}{v},
$$

where: $v$ - ship's speed in the approach channel; $v_{d}$ - drift speed of the ship perpendicular to the channel access can be calculated in the following way:

$$
v_{d}=v_{a} \cdot \sqrt{\frac{C_{a} \cdot \rho_{1} \cdot S_{x}}{C_{y} \cdot \rho \cdot F_{d}}} \cdot \sin q_{a} \cdot \frac{1}{k_{22 s}},
$$

where: $v_{a}$ - wind velocity; $C_{a}$ - aerodynamic coefficient $\left(C_{a}=1.07\right) ; \rho_{1}-$ air density $\left(\rho_{1}=1.25 \mathrm{~kg} / \mathrm{m}^{3}\right) ; S_{x}-$ the space of projection (upper water) onto a diametrical plane of the wind surface area of the vessel; $C_{y}$ - hydrodynamic coefficient $\left(C_{y}=1.5\right) ; \rho$ - water density; $F_{d}$ - the space of projection onto a diametrical plane of the underwater area of the vessel; $q_{a}$ - the $90^{\circ}$ course angle of the wind for design tasks on the approach channel could be taken; $k_{22 s}$ - resistance coefficient of a ship in the perpendicular direction to the axis of the approach channel on shallow water.

The resistance coefficient of the ship in the perpendicular direction to the axis of the approach channel on shallow water has been studied in different channels and in open sea areas, which means that approach channels mainly are open channels. Study and the experimental results of real ships are shown in Figure 5.

The resistance coefficient of the ship, in case of ship movement on the perpendicular direction, could be calculated using the regression equation:

$$
k_{22 s}=1+4.95 \cdot\left(\frac{T}{H}\right)^{2} ; R^{2}=0.93,
$$

where: $T$ - ship's average draft; $H$ - depth of the approach channel; $R^{2}$ - determination coefficient.

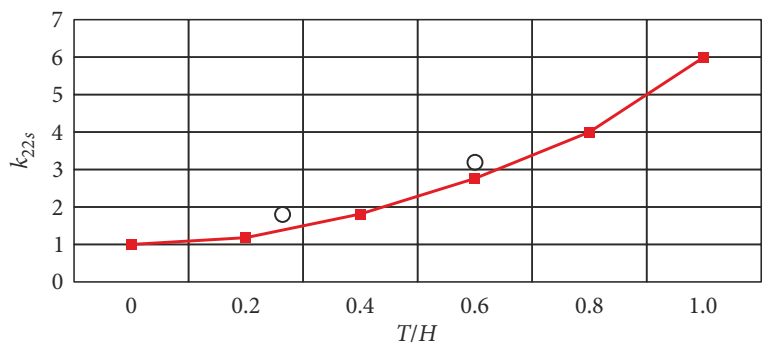

Figure 5. The additional resistance coefficient of the ship $k_{22 s}$ is subject to the ship's draft to depth ratio $T / H$; $\mathrm{o}$ - calculation and experimental results

For approach channels, recommendations on width calculation, for example PIANC (2014), could be used. According to PIANC (2014) recommendations, the width of the approach channel could be calculated as follows:

$$
B_{K}=B_{B M}+\sum B_{i}+B_{B R}+B_{B G},
$$

where: $B_{B M}$ - ship's basic manoeuvring line could range from $1.3 \cdot B$ to $1.88 \cdot B$ ( $B$ - biggest ship's breadth) and depends of ship manoeuvrability; $B_{i}$ - additional corrections to the width of the approach channel on straight sections could range from 0 to $1 \cdot B$ depending on the permitted ship's speed, privileged wind, current velocity and direction, wave characteristics, the aids of navigation characteristics, the depth and types of cargo; $B_{B R}, B_{B G}$ - distances to shallow water on the right and left sides of the channel subject to the slops of the approach channel and ship's speed (vary from $0.3 \cdot B$ to $1.0 \cdot B$ ).

Today, simulators are frequently used for testing the approach channel and other water ways (FT 2016). The accuracy of the received results are subject to the reliability of ship models and the simulation of external conditions. The human factor is implemented in real time simulation, and therefore it matters who is handling the ship in the given terms and conditions, because the obtained results strongly depend on the experience of a simulator operator. Simulation needs to be repeated (wind, current speed and direction, wave characteristics, etc.) a certain number of times under the same external conditions to collect appropriate data on calculating channel width. In order to receive the final results of the width of the approach channel provided by simulators, the maximum distribution method could be used and expressed as follows (Paulauskas 2013):

$$
B_{k}=B+P \cdot k_{n} \cdot R_{n}
$$

where: $B_{k}$ - width of the approach channel; $B$ - maximum width of the biggest ship; $P$ - factor in probabilistic maintenance (in the case of \pm 1 , probability is $68.3 \%$, in the case of \pm 2 , probability is $95.3 \%$ and in the case of \pm 3 , probability is $99.7 \%) ; k_{n}$ - the coefficient depends of the number of measurements (in case the number of measurements is $3, k_{n}=0.55$; when the number of measurements is 4 , $k_{n}=0.47$; when the number of measurements is $5, k_{n}=$ 0.43 ; when the number of measurements is $6, k_{n}=0.395$; 
when the number of measurements is $7, k_{n}=0.37$; when the number of measurements is $8, k_{n}=0.351$; when the number of measurements is $9, k_{n}=0.337$; when the number of measurements is $10, k_{n}=0.329$; when the number of measurements is $11, k_{n}=0.325$; when the number of measurements is $\left.12, k_{n}=0.322\right) ; R_{n}$ - the distribution of measurement results means the difference between minimum and maximum measurements results.

The presented theoretical dependencies and recommendations could be used for evaluating approach channels to different ports and for making an attempt to find reasons for differences to be overtaken, including navigational systems and equipment considering hydro-meteorological conditions, professional abilities of port pilots, historical traditions, etc.

\section{Case study on calculating the width of the approach channel to the port}

The approach channel to the Port of Klaipeda has been taken as a case study and evaluated applying the theoretical method, tested using SimFlex 4 simulators (FT 2016) and checked with reference to the real ships entering and departing the port. According to the conditions specified in the theoretical part of the article, the width of the approach channel to the port is calculated additionally under the condition that the drift angle of the SUEZMAX ship (290 $\mathrm{m}$ in length and $48 \mathrm{~m}$ in width) is accepted to be $4^{\circ}$ and the angle of the steering accuracy of the ship is $3^{\circ}$ (when cross wind is $14 \mathrm{~m} / \mathrm{s}$ ). Navigational reserve at $0.5 \cdot B$ on both sides is taken. The accuracy of positioning the vessel in the approach channel is approximately $8 \mathrm{~m}$ using the leading (bearing) line and the Differential Global Positioning System (DGPS). The probability of vessel positioning of the SUEZMAX tanker is taken not less than 99.7\%.

Considering theoretical calculations, $T / H$ is around 0.8 , and the width of the approach channel for the SUEZMAX tanker is $151 \mathrm{~m}$. The same calculations were made for POST PANAMAX ( $L=250 \mathrm{~m}, B=44 \mathrm{~m})$ and PANAMAX $(L=220 \mathrm{~m}, B=32 \mathrm{~m})$ ships.

According to PIANC (2014) recommendations, it is necessary to assess all possible effects. Potential impacts and their sizes of the approach channel, according to PIANC (2014) recommendations, are presented in Table. The same calculations of POST PANAMAX and PANAMAX ships have been also done.

Simulation testing using the SimFlex 4 simulator (FT 2016) has been made in the approach channel of the Port of Klaipeda taking into consideration the biggest possible ships under limited hydro-meteorological conditions. The examples of simulation are presented in the Figure 6.

7 simulation cases of the SUEZMAX ship entering port under similar hydro-meteorological conditions (SW wind of $14 \mathrm{~m} / \mathrm{s}$, wave height was up to $2.5 \mathrm{~m}$ in the approach channel) were made, and the results of the received distribution were equal to $R_{n}=0.55 \mathrm{~m}$. The width of the approach channel was calculated applying Equation (6) in the case of $99.7 \%$ probability, the width of the channel has to make not less than $109.1 \mathrm{~m}$. The same simulations were made for POST PANAMAX and PANAMAX ships.

During 10 months (in 2016 and 2017), SUEZMAX, POST PANAMAX and PANAMAX ships entering the Port of Klaipeda were checked. The trajectories of the approach channel were defined employing the Automatic Identification System (AIS) and port radar (in total, $12 \ldots 15$ ship entries to the port), SW and W wind directions were mainly prevailing and wind speed varied from 8 to $12 \mathrm{~m} / \mathrm{s}$. The example of the trajectory followed by SUEZMAX ships entering the port was received using the AIS presented in the Figure 7.

The distribution of the trajectory followed by the SUEZMAX ship included 12 entries to the port and made $R_{n}=0.47 \mathrm{~m}$. Calculating the width of the approach channel employing Equation (6) in the case of $99.7 \%$ probability points out the width of the channel equal to $93.4 \mathrm{~m}$.

The width of approach channels to ports for different ships, under limiting sailing conditions, was obtained with reference to PLANC (2014) recommendations, simulations, applying the maximum distribution method and estimating sailing parameters for real ships entering and leaving approach channels to ports.

The analysis of calculating the width of different approach channels to ports and the results of evaluation methods are presented in Figure 8.

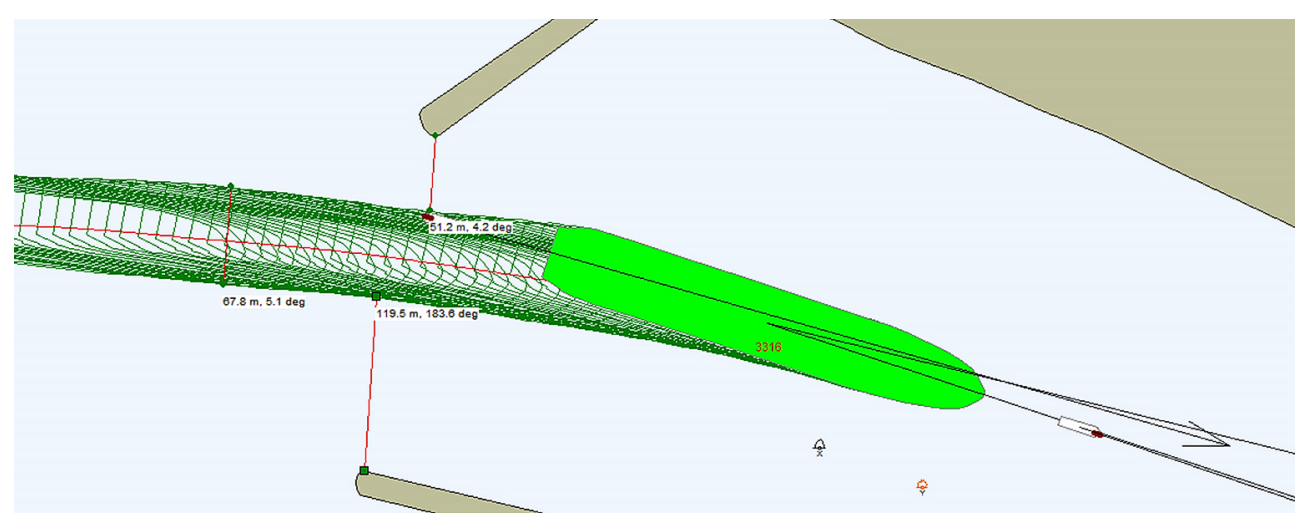

Figure 6. The SUEZMAX tanker entering the port under the SW wind of $14 \mathrm{~m} / \mathrm{s}$ and measurements made using the SimFlex 4 simulator (FT 2016) 


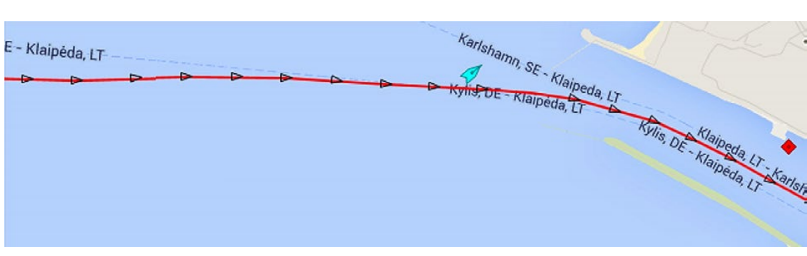

Figure 7. The entry of the SUEZMAX ship following the port trajectory was obtained employing the AIS

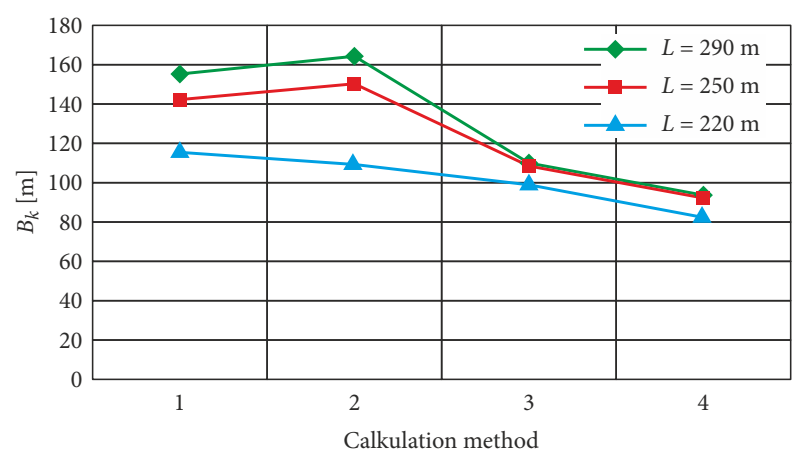

Figure 8 . The width of the approach channel to the port for SUEZMAX $(L=290 \mathrm{~m})$, POST PANAMAX $(L=250 \mathrm{~m})$

and PANAMAX $(L=220 \mathrm{~m})$ ships was obtained by:

1 - calculation, 2 - PIANC (2014) recommendations,

3 - simulations, 4 - experiments on real ships methods for limit conditions (wind of up to $14 \mathrm{~m} / \mathrm{s}$ in the perpendicular direction, waves were up to $2.5 \mathrm{~m}$ )

Table. The width of the approach channel for the SUEZMAX tanker $(B=48 \mathrm{~m})$ according to PIANC (2014) recommendations

\begin{tabular}{|l|c|}
\hline \multicolumn{1}{|c|}{ Effect } & $\begin{array}{c}\text { Width of the } \\
\text { approach channel }\end{array}$ \\
\hline$B_{B M}$ & $1.5 \cdot B$ \\
\hline Ship's speed $(6 \ldots 10 \mathrm{knots})$ & 0 \\
\hline Wind velocity $(7 \ldots 12 \mathrm{~m} / \mathrm{s})$ & $0.4 \cdot B$ \\
\hline Cross current speed $(0.2 \ldots 0.5 \mathrm{knots})$ & $0.2 \cdot B$ \\
\hline Longitudinal current speed up to 3 knots & 0 \\
\hline Wave height up to $3 \mathrm{~m}$ & $0.5 \cdot B$ \\
\hline Bottom soil & $0.1 \cdot B$ \\
\hline Depth correction & $0.2 \cdot B$ \\
\hline Slops & $0.5 \cdot B$ \\
\hline$B_{K} / B$ & $3.4 \cdot B$ \\
\hline$B_{k}[\mathrm{~m}]$ & 163.2 \\
\hline
\end{tabular}

The results presented in Figure 8 show that the calculation method and PIANC (2014) recommendations are very close, and the results of the simulation method and the experimental results of real ships are important for safety evaluation. The analysis of the real width of approach channels to different ports show that the width of approach channels is between calculation and simulation or real experimental results (Rostock, Gdynia, Dunkerk ports), and in some ports - closer to calculation results or PIANC (2014) recommendations.

\section{Conclusions}

The analysis of different methods for calculating the width of the approach channel to the port demonstrates that the theoretical calculation method for the approach channel to the port could be successfully applied under the final additional safety coefficient of 1.5 .

Simultaneously, the theoretical calculations of the width of the approach channel to the port and PIANC (2014) recommendations, in the case of limiting conditions taken in theoretical calculations, are very close. The simulation done employing a good calibrated simulator could be used for clarifying theoretical calculations due to the included human factor and in the case a number of people (ships masters or port pilots) are involved in the action.

The experimental results of estimating sailing parameters for real ships and the width of the approach channel to the port are very important because real findings could include local conditions.

Thus, it is possible to sum up that different countries and ports use various methods for calculating the width of approach channels to ports but the theoretical calculation method could be taken as the most effective technique though it has to be verified employing other methods.

\section{References}

Farzaneh, O.; Askari, F.; Ganjian, N. 2008. Three-dimensional stability analysis of convex slopes in plan view, Journal of Geotechnical and Geoenvironmental Engineering 134(8): 1192-1200.

https://doi.org/10.1061/(ASCE)1090-0241(2008)134:8(1192)

FT. 2016. SimFlex 4. FORCE Technology (FT), Denmark. 120 p.

Grabe, J. (Ed.). 2015. Recommendations of the Committee for Waterfront Structures Harbours and Waterways EAU 2012. Wilhelm Ernst \& Sohn. 600 p. https://doi.org/10.1002/9783433605172

Groeneveld, R.; Beimers, B.; Vis, F. C. 2003. A simple method to assess nautical risks, in 6th Conference on Coastal and Port Engineering in Developing Countries: COPEDEC VI, 14-19 September 2003, Colombo, Sri Lanka, 125-126.

Gucma, L.; Montewka, J. 2005. Landborne laser rangefinder measurements for navigation safety assessment, European Journal of Navigation 3(4): 1-6.

Lee, C.-K.; Lee, S.-G. 2008. Investigation of ship maneuvering with hydrodynamic effects between ship and bank, Journal of Mechanical Science and Technology 22(6): 1230-1236. https://doi.org/10.1007/s12206-008-0309-9

McBride, M. W.; Smallman, J. V.; Huntington, S. W. 1998. Guidelines for design of approach channels, in Ports'98: Conference Proceedings, 8-11 March 1998, Long Beach, CA, US, 13151324.

Ohtsu, K.; Yoshimura, Y.; Hirano, M.; Tsugane, M.; Takahashi, H. 2006. Design standard for fairway in next generation, in Asia Navigation Conference 2006, 20-21 October 2006, Jeju, Korea, 230-239.

OpenSeaMap. 2018. OpenSeaMap - the Free Nautical Chart. Available from Internet:

http://www.openseamap.org/index.php?id=openseamap\&L=1 
Paulauskas, V. 2006. Navigational risk assessment of ships, Transport (21)1: 12-18.

https://doi.org/10.3846/16484142.2006.9638034

Paulauskas, V. 2013. Ships Entering the Port: Monograph. Riga: N.I.M.S. 240 p.

Paulauskas, V.; Paulauskas, D. 2009. Laivo valdymas uoste. Klaipeda: Klaipedos universiteto leidykla. 256 p. (in Lithuanian).

PIANC. 2014. Harbour Approach Channels Design Guidelines. PIANC Report No 121. Permanent International Association of Navigational Congresses (PIANC). 320 p.

Puertos del Estado. 1999. ROM 3.1-99: Recommendation for Design of the Maritime Configuration of Ports, Approach Channels and Harbour Basins. Puertos del Estado [Ports of the State], Madrid, Spain. 382 p. Available from Internet: http://www. puertos.es/eu-es/BibliotecaV2/ROM\%203.1-99\%20(EN).pdf

Zalewski, P.; Montewka, J. 2007. Navigation safety assessment in an entrance channel, based on real experiments, in Proceedings of the 12th International Congress of the International Maritime Association of the Mediterranean (IMAM 2007), 2-6 September 2007, Varna, Bulgaria, 1113-1120. 